\title{
An isopentyl transferase gene driven by the senescence-inducible SAG12 promoter improves salinity stress tolerance in cotton
}

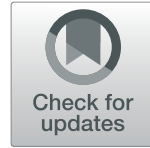

\author{
SHAN Yi ${ }^{\dagger}$, ZHAO Peng ${ }^{\dagger}$, LIU Zhao, LI Fangjun ${ }^{*}$ and TIAN Xiaoli
}

\begin{abstract}
Background: Soil salinity seriously affects cotton growth, leading to the reduction of yield and fiber quality. Recently, genetic engineering has become an efficient tool to increase abiotic stress tolerance in crops.

Results: In this study, isopentyl transferase (IPT), a key enzyme involved in cytokinin (CTK) biosynthesis from Agrobacterium tumefaciens, was selected to generate transgenic cotton via Agrobacterium-mediated transformation. A senescence-inducible SAG12 promoter from Arabidopsis was fused with the IPT gene. Ectopic-expression of SAG12:IPT significantly promoted seed germination or seedling tolerance to salt stress. Two IPT transgenic lines, OE3 as a tolerant line during seed germination, and OE8 as a tolerant line at seedling stage, were selected for further physiological analysis. The data showed that ectopic-expression of SAG12::IPT induced the accumulation of CTKs not only in leaves and roots, but also in germinating seeds. Moreover, ectopic-expressing IPT increased the activity of antioxidant enzymes, which was associated with the less reactive oxygen species (ROS) accumulation compared with control plants. Also, ectopic-expression of IPT produced higher $\mathrm{K}^{+} / \mathrm{Na}^{+}$ratio in cotton shoot and root.

Conclusion: The senescence-induced CTK accumulation in cotton seeds and seedlings positively regulates salt stress partially by elevating ROS scavenging capability.
\end{abstract}

Keywords: Isopentyl transferase (IPT), Cytokinin (CTK), Transgenic, Salt tolerance, Cotton

\section{Background}

Salt stress can interfere with plant growth and development. High concentration of $\mathrm{Na}^{+}$reduces water potential in the soil, and affects the absorption of other ions to disturb the ion homeostasis in plant cells. Furthermore, salt stress promotes accumulation of reactive oxygen species (ROS) in plants, which results in oxidative damage (Das and Roychoudhury 2014).

Cytokinins (CTKs) play an important role not only in plant growth and development, but also in response to abiotic stresses (Ha et al. 2012; Zwack and Rashotte 2015). Previous studies have revealed that plants either treated with exogenous CTKs or producing more endogenous CTKs have both positive and negative effects on abiotic stress tolerance (Zwack and Rashotte 2015). CTKs can directly or indirectly scavenge superoxide free

\footnotetext{
* Correspondence: lifangjun@cau.edu.cn

${ }^{\dagger} \mathrm{Yi}$ SHAN and Peng ZHAO contributed equally to this work.

College of Agronomy and Biotechnology, China Agricultural University, Beijing 100193, China
}

radicals $\left(\mathrm{O}_{2}^{-}\right)$that induced by abiotic stresses (Leshem et al. 1981). Moreover, CTKs change the proportion of the membrane lipid peroxidation products and membrane fatty acids, which maintains the integrity of cell membrane, and increases the activity of antioxidant enzymes such as peroxidase (POD), superoxide dismutase (SOD), ascorbate peroxidase (APX), and catalase (CAT) (Wojtania and Skrzypek 2014).

The isopentenyl transferase (IPT) gene from Agrobacterium tumfaciens encodes a rate-limiting enzyme in the adenosine monophosphate (AMP) pathway of CTK biosynthesis (Akiyoshi et al. 1984; Takei et al. 2001; Belintani et al. 2012), which catalyzes the first step in the $a b$ initio synthesis of CTKs. With the help of IPT, the isoamyl groups (DMAPP) are transferred to the $\mathrm{N}^{6}$ site of AMP, which produces isopentyl adenosine-5- $\beta$-phosphate (iPMP) and isopentenyl adenosine (iPA). Then, iPMP is converted into other types of CTKs, such as zeatin riboside (ZR) (Kakimoto 2001; Takei et al. 2001). 
Senescence-associated $(S A G)$ gene is a senescence related gene. Transgenic plants with SAG12::IPT have delayed leaf senescence (Yuan et al. 2002; Zakizadeh et al. 2013) and enhanced drought resistance (Rivero et al. 2007; Merewitz et al. 2010). However, estradiolinducible overexpression of AtIPT8 in Arabidopsis are more sensitive to salt stress due to enhanced ROS generation and decreased activities of ROS-scavenging enzymes (Wang et al. 2015).

Cotton is a worldwide cash crop as it produces fiber, seed oil, feed, and biofuel (Sunilkumar et al. 2006). In general, cotton is considered to be more drought- and salt-tolerant compared with other crops. However, salt tolerance differs greatly among cotton varieties and phenotypes (Ashraf 2002; Ohkama-Ohtsu et al. 2007; Iqbal et al. 2011). Recently, several stress-related genes were transformed into cotton to improve abiotic-stress tolerance. Overexpression of the Arabidopsis vacuolar $\mathrm{H}^{+}$pyrophosphatase gene AVP1 improves both drought and salt tolerance in cotton (Pasapula et al. 2015). Cotton transformed with the maize bZIP transcription factor $A B P 9$ shows resistant to drought and salt stresses (Wang et al. 2017). Overexpressing the rice NAC gene SNAC1 improves salt and drought tolerance in cotton through enhancing root development and reducing transpiration rates (Liu et al. 2014); and overexpression of the rice SUMO E3 ligase OsSIZ1 enhances net photosynthesis to improve drought and heat tolerance in cotton (Mishra et al. 2017). Furthermore, overexpression of SAG12::IPT delays leaf senescence (Liu et al. 2012a; Liu et al. 2012b; Zhao et al. 2012). Here, we found that SAG12::IPT transgenic cotton plants produced more CTKs and less ROS accumulation in response to salt stress. Thus, our study provided new cotton lines tolerant to salt stress via genetic engineering.

\section{Materials and methods}

\section{Plant materials and growth conditions}

Upland cotton (Gossypium hirsutum L.) JIHE321 was used as control plants. The plasmid pSG529 constructed at the Richard M. Amasino Laboratory at the University of Wisconsin-Madison was donated by FU Yongcai, an associate professor at China Agricultural University. The plasmid was constructed with IPT gene driven by a senescence-inducible SAG12 promoter, and possesses NTPII marker gene for selection. Positive SAG12::IPT transgenic cotton lines were obtained by Agrobacteriummediated transformation with the help of the Cotton Research Institute of Shanxi Academy of Agricultural Sciences. Four transgenic cotton lines (OE3, OE6, OE7, and OE8) and JIHE321 were planted at growth room with conditions of $(30 \pm 2)^{\circ} \mathrm{C}$ day $/(24 \pm 2)^{\circ} \mathrm{C}$ night, $70 \sim 80 \%$ relative humidity, $14 \mathrm{~h}$ light $/ 10 \mathrm{~h}$ dark, and $600 \mu \mathrm{mol} \cdot \mathrm{cm}^{-2} \cdot \mathrm{s}^{-1}$ photosynthetically active radiation.

\section{Salinity stress treatment}

Salinity stress during germination: after being surfacesterilized by soaking in $9 \% \mathrm{H}_{2} \mathrm{O}_{2}$ for $30 \mathrm{~min}$, cotton seeds were soaked in 150 and $200 \mathrm{mmol} \cdot \mathrm{L}^{-1} \mathrm{NaCl}$ solution for $24 \mathrm{~h}$. The seeds were then wrapped with germination paper which was pre-soaked with the corresponding $\mathrm{NaCl}$ solution and placed in a germination box containing the corresponding $\mathrm{NaCl}$ solution in the dark.

Salinity stress at seedling stage: after being surfacesterilized by soaking in $9 \% \mathrm{H}_{2} \mathrm{O}_{2}$ for $30 \mathrm{~min}$, seeds were rinsed with tap water and germinated in sand for 4 days in the dark. After germination, seedlings at uniform growth stage were transplanted into halfstrength modified Hoagland's solution containing 2.5 $\mathrm{mmol} \cdot \mathrm{L}^{-1} \quad \mathrm{Ca} \quad\left(\mathrm{NO}_{3}\right)_{2}, \quad 2.5 \mathrm{mmol} \cdot \mathrm{L}^{-1} \quad \mathrm{~K}_{2} \mathrm{SO}_{4}, \quad 1$ $\mathrm{mmol} \cdot \mathrm{L}^{-1} \quad \mathrm{MgSO}_{4}, \quad 500 \mu \mathrm{mol} \cdot \mathrm{L}^{-1} \quad\left(\mathrm{NH}_{4}\right) \mathrm{H}_{2} \mathrm{PO}_{4}$, $0.2 \mu \mathrm{mol} \cdot \mathrm{L}^{-1} \mathrm{CuSO}_{4}, 1 \mu \mathrm{mol} \cdot \mathrm{L}^{-1} \mathrm{ZnSO}_{4}, 100 \mu \mathrm{mol} \cdot \mathrm{L}^{-1}$ FeNaEDTA, $20 \mu \mathrm{mol} \cdot \mathrm{L}^{-1} \quad \mathrm{H}_{3} \mathrm{BO}_{3}, \quad 5 \times 10^{-3} \mu \mathrm{mol} \cdot \mathrm{L}^{-1}$ $\left(\mathrm{NH}_{4}\right)_{6} \mathrm{Mo}_{7} \mathrm{O}_{24}$, and $1 \mu \mathrm{mol} \cdot \mathrm{L}^{-1} \mathrm{MnSO}_{4}$ (Wang et al. 2012). The solutions were aerated and changed twice a week. The seedlings were treated with $220 \mathrm{mmol} \cdot \mathrm{L}^{-1}$ $\mathrm{NaCl}$ at the three-leaf stage.

\section{Germination energy and germination rate}

The number of germinated seeds was checked daily to calculate the seed germination energy and germination rate according to the following formulas.

$$
\begin{aligned}
\text { Germinationenergy }= & (\text { Germination numberat first three days } / \\
& \text { Total number of seeds tested }) \times 100 \%
\end{aligned}
$$

Germinationrate $=$ (Germination number at first seven days $/$ Total number of seeds tested) $\times 100 \%$

\section{Measurement of chlorophyll content}

Salt stressed cotton seedlings were used to measure chlorophyll content. The third true leaf (approximately $0.1 \mathrm{~g}$ ) of transgenic cotton lines and the JIHE321 were collected to determine chlorophyll content following Tang et al. (2005).

\section{Measurement of CTK content}

For the salinity stress experiments performed during germination, whole germinating seeds (those with the seed coat were removed) were sampled after one, two, three, and five days of germination, and the germinating seeds sampled at the seventh day were separated into shoots and roots. For the salinity stress experiments performed at the seedling stage, the third true leaf and roots were collected after one, three, and six days of 220 $\mathrm{mmol} \cdot \mathrm{L}^{-1} \mathrm{NaCl}$ treatment. Endogenous zeatin (Z)/ZR and iP/iPA were determined using ELISA assay following Dong et al. (2008). The mouse monoclonal antigen 
and antibodies were produced at the Center of Crop Chemical Control, China Agricultural University.

\section{Analysis of $\mathrm{H}_{2} \mathrm{O}_{2}$ content and the activity of antioxidant enzymes in cotton leaves}

The third leaf from the $\mathrm{NaCl}$ treated seedlings were collected at the indicated time points as described above. The $\mathrm{H}_{2} \mathrm{O}_{2}$ content was measured according to $\mathrm{Hu}$ et al. (2012), and POD and SOD activity were detected following Zaharieva et al. (1999) and Dhindsa et al. (1981), respectively.

\section{Measurement of $\mathrm{K}^{+} / \mathrm{Na}^{+}$ratio}

After seven days of $220 \mathrm{mmol} \cdot \mathrm{L}^{-1} \mathrm{NaCl}$ treatment, the third true leaf and roots were collected and dried at $80^{\circ} \mathrm{C}$, finely grounded, and digested with $1 \mathrm{mmol} \cdot \mathrm{L}^{-1} \mathrm{HCl}$ at $30{ }^{\circ} \mathrm{C}$ for $24 \mathrm{~h}$. The $\mathrm{Na}^{+}$and $\mathrm{K}^{+}$contents were determined using an atomic absorption spectrophotometer
SpectAA-50/55 (Varian, Australia). The $\mathrm{K}^{+} / \mathrm{Na}^{+}$ratio was calculated by dividing $\mathrm{K}^{+}$content by $\mathrm{Na}^{+}$content.

\section{Data analysis}

All experiments were repeated three times, and each treatment had at least three replicates. Data were pooled according to one representative experiment. Analysis of variance (ANOVA) was performed using the General Linear Model procedure (GLM) in the SPSS 21.0 (SPSS Inc., Chicago IL, USA). Mean values were compared using Duncan's multiple range tests at the $5 \%$ level of probability.

\section{Results}

Ectopic-expression of SAG12::IPT promotes cotton seed germination under salt stress

In this study, we generated transgenic cotton lines with SAG12::IPT vector (Fig. 1a). Among nine transgenic lines, four lines (OE3, OE6, OE7, and OE8) showed strong tolerance to salt stress, which were selected for

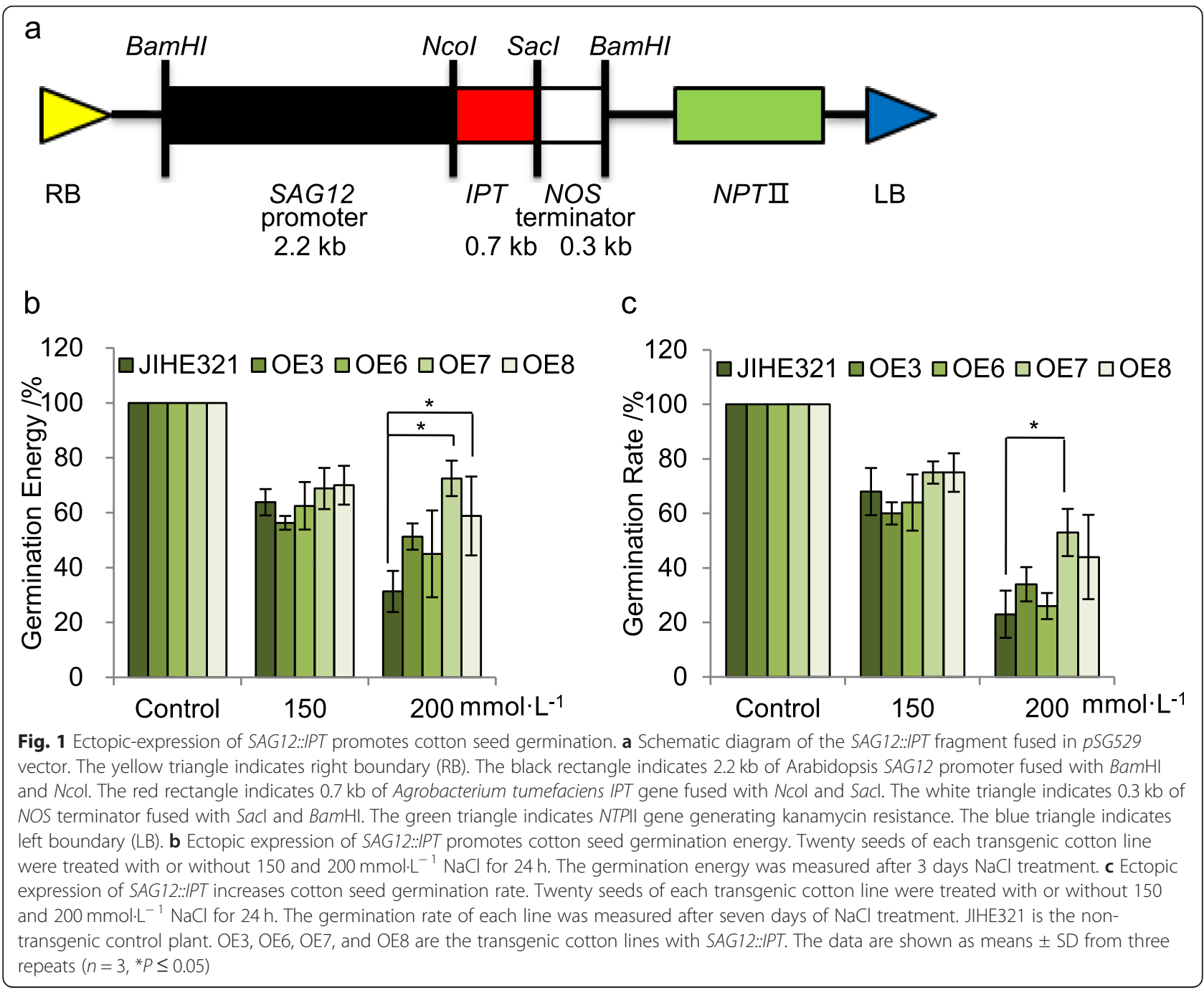


further investigation. We calculated the germination energy and germination rate of transgenic cotton lines whose seeds were exposed to 150 and $200 \mathrm{mmol} \cdot \mathrm{L}^{-1}$ $\mathrm{NaCl}$, and found that both germination energy and germination rate decreased dramatically in a $\mathrm{NaCl}$ dosage dependent manner (Fig. 1). However, ectopic-expression of SAG12::IPT alleviated the inhibition of seed germination caused by $\mathrm{NaCl}$ with respect to control plants of JIHE321 (Fig. 1). Particularly, OE7 and OE8 lines showed more germination energy (Fig. 1b) and OE7 showed higher germination rate (Fig. 1c).

\section{Ectopic-expression of SAG12::IPT increases salt tolerance of cotton seedlings}

After being surface-sterilized by soaking in $9 \% \mathrm{H}_{2} \mathrm{O}_{2}$ for $30 \mathrm{~min}$, seeds were rinsed with tap water and then germinated in sand medium for 4 days in the dark. After germination, transgenic cotton lines OE3 and OE6 and the control JIHE321 were planted into half-strength modified Hoagland's solution without $\mathrm{NaCl}$ treatment. The seedlings at the three-leaf stage were then treated with $220 \mathrm{mmol} \cdot \mathrm{L}^{-1} \mathrm{NaCl}$. The salt phenotype was recorded after 6 days of $\mathrm{NaCl}$ treatment (Fig. 2a). Approximately $0.1 \mathrm{~g}$ of the third leaf of transgenic cotton lines and JIHE321 were collected to determine chlorophyll content after $220 \mathrm{mmol} \cdot \mathrm{L}-1 \mathrm{NaCl}$ treatment for seven days (Fig. 2b). As shown in Fig. 2, ectopic-expression of SAG12::IPT strongly enhanced the tolerance of cotton seedlings to $220 \mathrm{mmol} \cdot \mathrm{L}^{-1} \mathrm{NaCl}$ treatment lasting for 6 days. The transgenic lines exhibited less defoliation, greener leaves, and had more chlorophyll content compared with JIHE321 (Fig. 2a \& b). Moreover, OE3 and OE6 lines showed greater tolerance than OE7 and OE8 lines.

\section{Ectopic-expression of SAG12::IPT increases CTK content during cotton seed germination}

We determined the CTK content in germinating seeds of OE3 line (more tolerant to salt during seed germination) and OE8 line (more tolerant to salt at seedling stage), and found that OE8 seeds showed significantly higher levels of Z/ZR compared with the control seeds after the first and second day of $220 \mathrm{mmol} \cdot \mathrm{L}^{-1} \mathrm{NaCl}$ treatment, and OE8 shoots (derived from germinating seeds) also had much more Z/ZR and iP/iPA ratios after the seventh day of $\mathrm{NaCl}$ treatment (Fig. 3a \& b). However, the differences in Z/ZR and iP/iPA contents between the $\mathrm{OE} 3$ and control lines were insignificant, which is consistent with the lower salt tolerance of the OE3 line compared with the OE8 line during seed germination.

\section{Ectopic-expression of SAG12::IPT increases CTK content in cotton seedlings}

In leaves, OE3 and OE8 lines had more Z/ZR and iP/ iPA than control plants after 3 days of $220 \mathrm{mmol} \cdot \mathrm{L}^{-1}$ $\mathrm{NaCl}$ treatment (Fig. 4a \& b). However, the differences of CTK level in roots between transgenic lines and the control did not appear until 6 days after $220 \mathrm{mmol} \cdot \mathrm{L}^{-1}$ $\mathrm{NaCl}$ treatment (Fig. 4c \& d). In particular, the OE3 line, which showed more tolerant to salt stress than the OE8

a
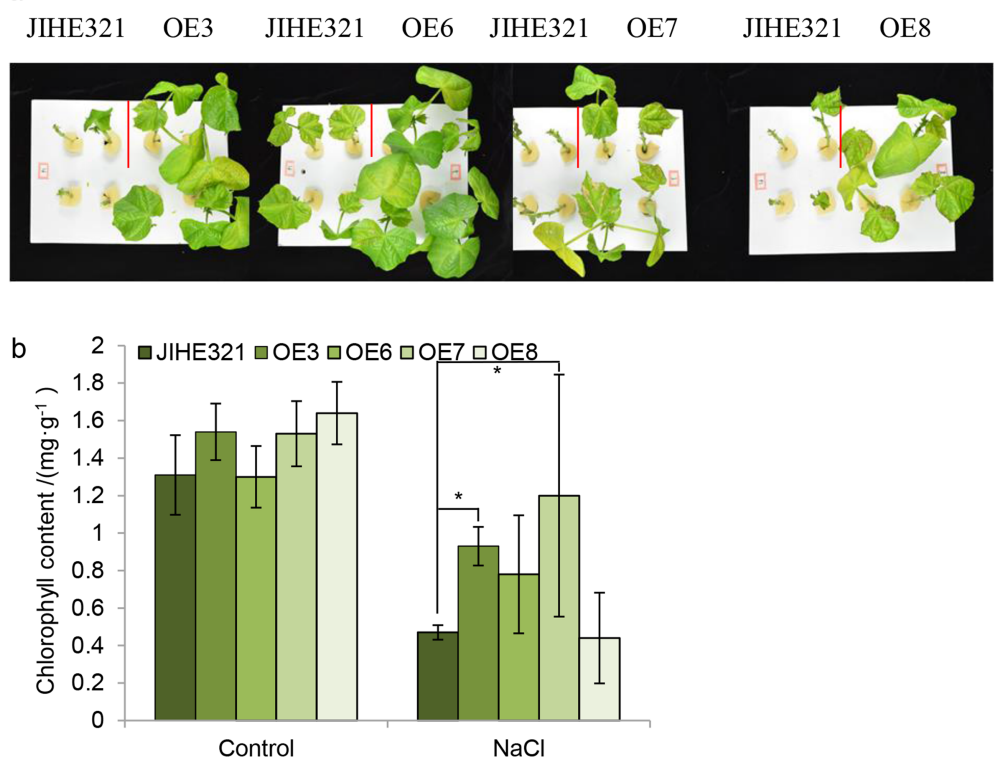

Fig. 2 Ectopic-expression of SAG12::IPT induces salt tolerance in cotton seedlings. a Ectopic expressing SAG12::IPT cotton plants are more tolerant to salt stress compared with JHHE321 control plants. b Ectopic expression of SAG12:.IPT induces chlorophyll content in cotton leaves. The data are shown as means $\pm \mathrm{SD}$ from three independent repeats $\left(n=3,{ }^{*} P<0.05\right)$ 

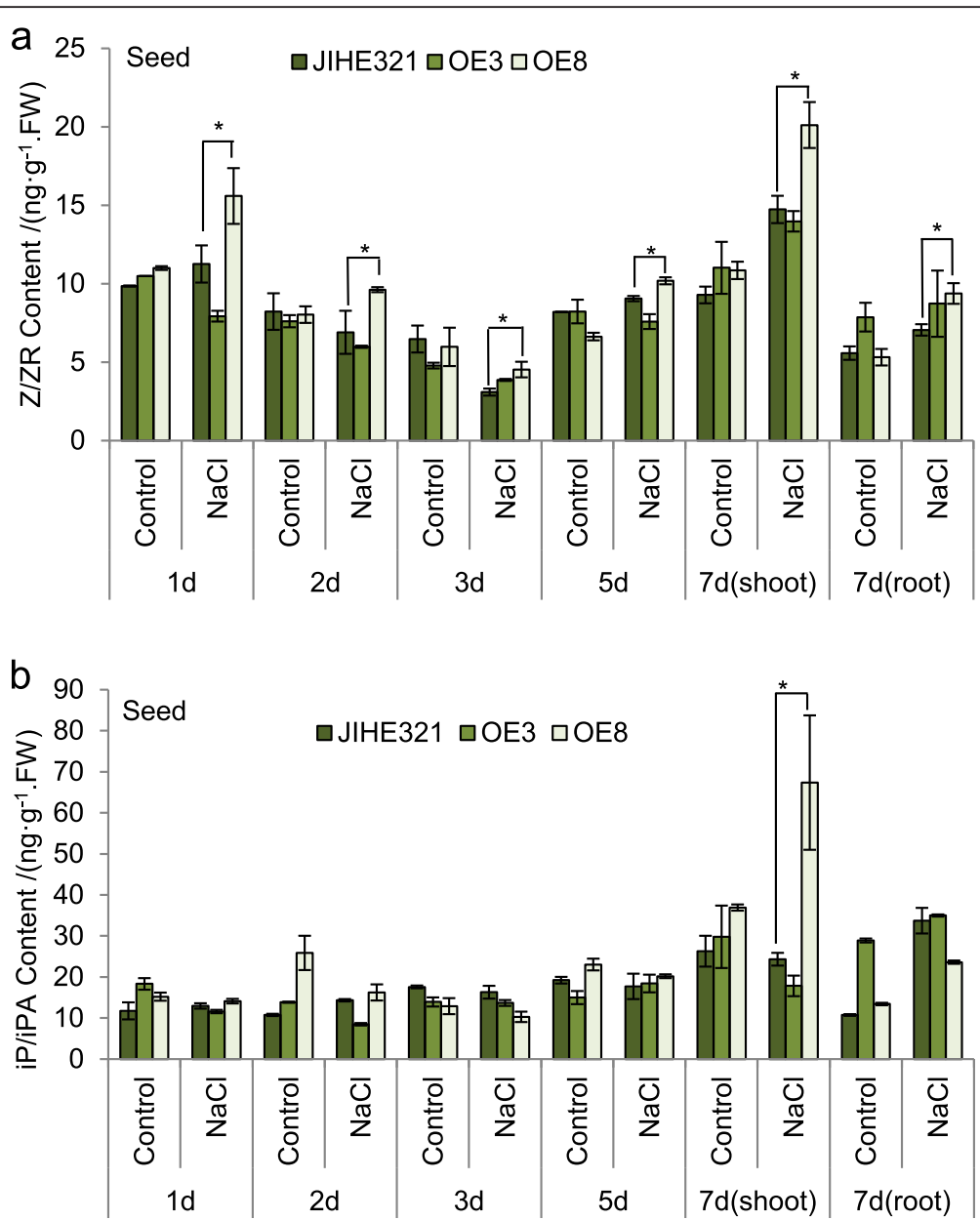

Fig. 3 Ectopic-expression of SAG12:.IPT induces cytokinin content in cotton seeds. a Ectopic expression of SAG12:.IPT induces Z/ZR-type cytokinin content in seeds of the OE3 and OE8 lines. Germinating seeds $(0.5 \mathrm{~g}$, without the seed coat) were sampled after one, two, three, and five days of germination; shoots and roots $(0.5 \mathrm{~g})$ separated from the germinating seeds with $220 \mathrm{mmol} \cdot \mathrm{L}^{-1} \mathrm{NaCl}$ treatment for seven days were collected to detect the Z/ZR-type cytokinin content. b Ectopic expression of SAG12:IPT induces IP/iPA-type cytokinin content in seeds of OE3 and OE8. The samples from (a) were used for the measurement of iP/PA-type cytokinin. The data are shown as means \pm SD from three repeats $\left(n=3,{ }^{*} P \leq 0.05\right)$

line at seedling stage, accumulated more $\mathrm{Z} / \mathrm{ZR}$ and $\mathrm{iP} /$ iPA than the OE8 line in both leaves (after the third day of $\mathrm{NaCl}$ treatment) and roots (after the sixth day of $\mathrm{NaCl}$ treatment). Together, the data suggested that senescence-inducible ectopic-expression of IPT induces salt tolerance in cotton seedlings likely by promoting CTK accumulation.

\section{Ectopic-expression of SAG12::IPT enhances ROS scavenging in cotton leaves under salt stress}

It is known that ROS triggered by salt stress affects protein physiological function in cells. In response, cells will activate the antioxidant enzymes, like SOD and POD to protect plants from oxidative stress (Mantri et al. 2011). In this study, the relative $\mathrm{H}_{2} \mathrm{O}_{2}$ content in the third leaf of cotton seedlings was determined, and data showed that the transgenic lines OE3 and OE8 had significantly less
$\mathrm{H}_{2} \mathrm{O}_{2}$ than control plants after 3 days of $220 \mathrm{mmol} \cdot \mathrm{L}^{-1}$ $\mathrm{NaCl}$ treatment (Fig. 5a). In addition, the leaves of the OE3 line (more tolerant to salt stress than OE8 line at seedling stage) had 409\% 414\% and 50\% 116\% more SOD and POD activity, respectively, than control plants during salt stress, and the leaves of the OE8 line showed $227 \%$ and $40 \%$ more SOD and POD activity than control plants after the first and the sixth day of salt stress, respectively (Fig. 5b \& c). The data indicated that maintaining high activity of ROS-scavenging system is one of the key mechanisms to protect plants from salt-induced ROS stress in ectopic-expressing IPT plants.

Ectopic-expression of SAG12::IPT maintains higher $\mathrm{K}^{+} / \mathrm{Na}^{+}$ ratio in leaves in response to salt stress

Maintaining the ion equilibrium of $\mathrm{Na}^{+}$and $\mathrm{K}^{+}$is a vital strategy to render plants tolerance of salt stress 

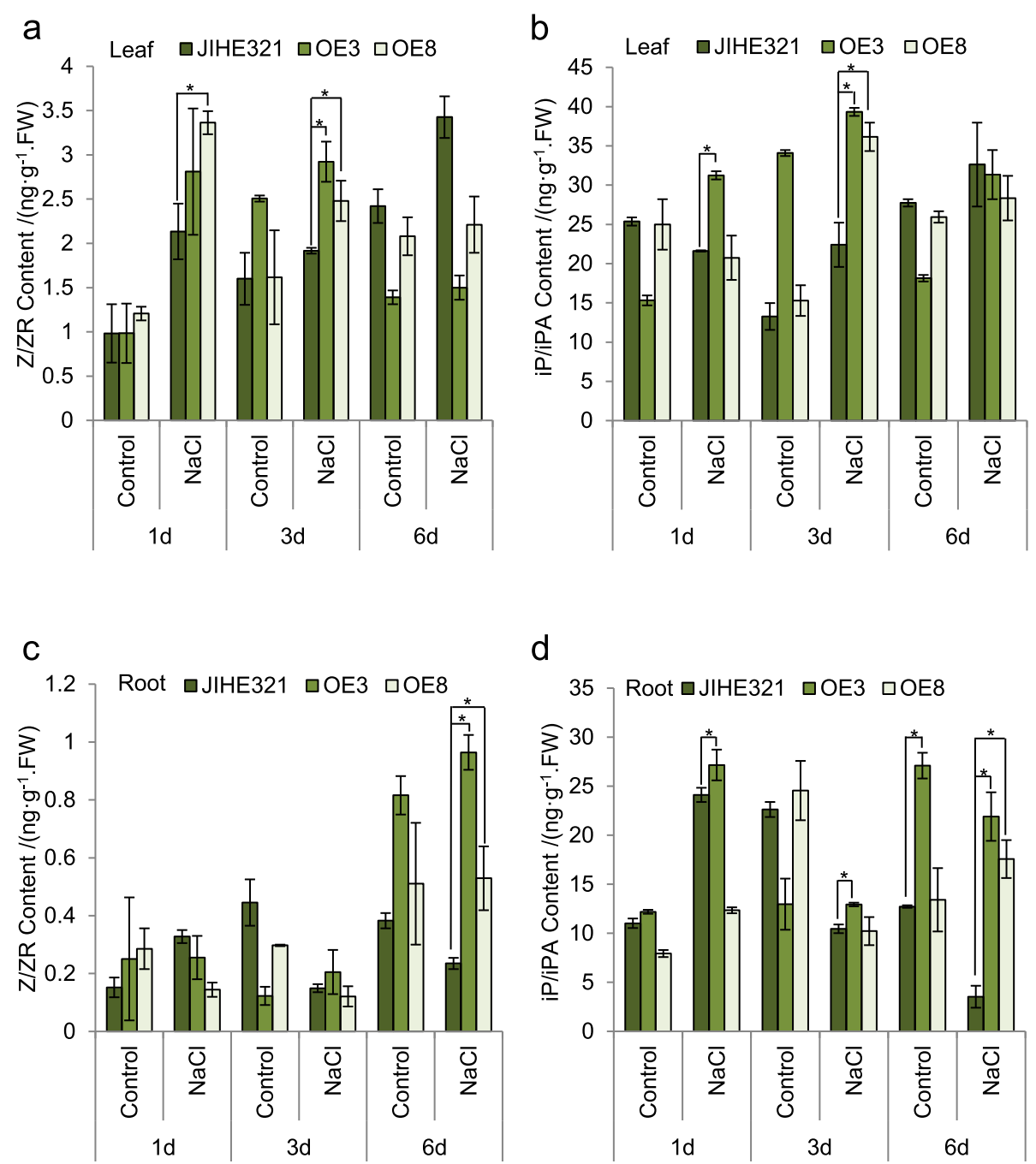

Fig. 4 Ectopic-expression of SAG12::IPT induces cytokinin content both in leaves and roots. a Ectopic expression of SAG12::IPT induces Z/ZR-type cytokinin content in the third true leaf of OE3 and OE8. The third true leaf $(0.5 \mathrm{~g})$ of transgenic lines and control cotton were collected after one, three and six days $220 \mathrm{mmol} \cdot \mathrm{L}^{-1} \mathrm{NaCl}$ treatment to detect Z/ZR-type cytokinin content. b Ectopic expression of SAG12:IPT induces iP/iPA-type cytokinin content in the third true leaf of OE3 and OE8. The samples were collected as (a). c Ectopic expression of SAG12:.IPT induces Z/ZR-type cytokinin content in roots of OE3 and OE8. The root samples $(0.5 \mathrm{~g})$ of transgenic lines and control cotton were collected after one, three and six days $220 \mathrm{mmol} \cdot \mathrm{L}^{-1} \mathrm{NaCl}$ treatment to detect Z/ZR-type cytokinin content. d Ectopic expression of SAG12::IPT induces iP/iPA-type cytokinin content in roots of OE3 and OE8. The samples were collected as (c). The data are shown as means \pm SD from three repeats $\left(n=3,{ }^{*} P \leq 0.05\right)$

(Feki et al. 2014). Compared with control plants, the OE3 line showed $79 \%$ higher $\mathrm{K}^{+} / \mathrm{Na}^{+}$ratio in leaves after 7 days of $220 \mathrm{mmol} \cdot \mathrm{L}^{-1} \mathrm{NaCl}$ treatment (Fig. 6), which may be responsible for its remarkable tolerance to salt stress. Moreover, the roots of the OE3 line, and both leaves and roots of the OE8 line had a slight, but significant higher $\mathrm{K}^{+} / \mathrm{Na}^{+}$ratio than those of control plants (Fig. 6).

\section{Discussion}

CTKs regulate various events in plant development and responses to environmental stimuli. In the twocomponent CTK signaling pathway, membrane-bound histidine kinases (HKs) perceive CTKs and cause HK auto-phosphorylation (Shi and Rashotte 2012). The signal is then transferred via histidine-containing phosphotransferase factors (AHPs), to transcription-factor-type response regulators (ARRs). Phosphorylation of B-type RRs (RRBs) activates GARP domain-containing transcription factors which positively regulate the expression of genes related to abiotic stresses (Mason et al. 2005). However, phosphorylated A-type RRs (RRAs), lacking a DNA-binding GARP domain, negatively regulate CTK signaling (Gupta and Rashotte 2012; Kieber and Schaller 2014). Moreover, HK mutants ahk2, ahk3 and their double mutants are more tolerant to salt stress 

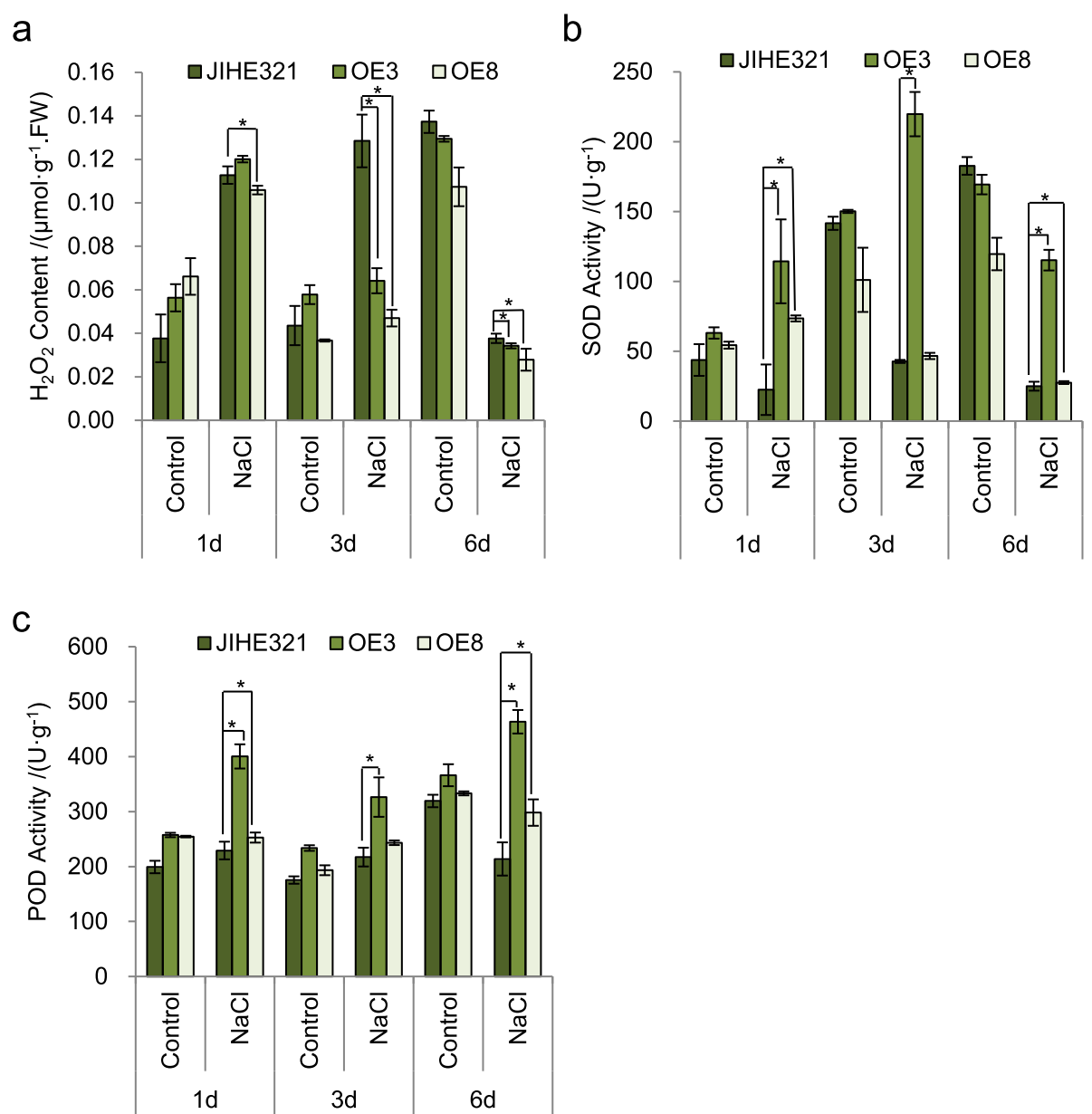

Fig. 5 Ectopic-expression of $S A G 12: .1 P T$ reduces relative $\mathrm{H}_{2} \mathrm{O}_{2}$ content, and enhances the activity of antioxidant enzymes in cotton leaves. a Ectopic expression of SAG12::IPT reduces relative $\mathrm{H}_{2} \mathrm{O}_{2}$ content in cotton leaves. The third leaf samples $(0.5 \mathrm{~g})$ of OE3 and OE8, and control plant were collected as Fig. 4 at indicated time points. b Ectopic expression of SAG12::IPT enhances SOD activity in the third leaf of OE3 and OE8. The samples were collected as (a). c Ectopic expression of SAG12::IPT enhances POD activity in the third leaf of OE3 and OE8. The samples were collected as (a). The data are shown as means \pm SD from three repeats $\left(n=3,{ }^{*} P \leq 0.05\right)$

(Tran et al. 2007), and RRBs double mutant arr1arr12 also shows enhanced salt tolerance (Mason et al. 2010), indicating a negative regulation of CTK signaling in response to salt stress. This negative regulation perhaps results from the hindered root development due to higher level of CTKs (Qiu et al. 2012).

However, if driven by inducible promoters such as light-inducible $r b c S-3 A$, cysteine proteinase, and salt inducible $R D 29 A$, overexpression of $I P T$ can enhance plant salt tolerance (Thomas et al. 1995; Liu et al.; Qiu et al. 2012). Consistently, we found that ectopic-expression of IPT under the control of a senescence-inducible promoter SAG12 induced endogenous CTKs and enhanced cotton salinity tolerance (Figs. $1 \& 2$ ). This could be because the temporarily increased endogenous CTKs can maintain normal cell growth under stress conditions, without affecting root growth.
Photosynthesis is one of the primary processes to be affected by salinity (Munns et al. 2006). Salt stress arises secondary oxidative stress, which can seriously affect leaf photosynthetic machinery (Ort 2001). Our study showed that overexpression of SAG12::IPT enhanced ROS scavenging ability (Fig. 5) and chlorophyll content (Fig. 2b) compared with JIHE321 control plants under salt stress, indicating that overexpressing SAG12::IPT enhanced salt tolerance likely through eliminating ROS accumulation to protect photosynthetic properties in cotton.

The reliable and stable expression of foreign genes is necessary for the successful application of genetic engineering in agriculture. However, many studies showed that the expression of the same foreign gene varies in different transgenic lines. In this study, we found that four SAG12::IPT transgenic cotton lines showed different responses to salt stress either during germination or 


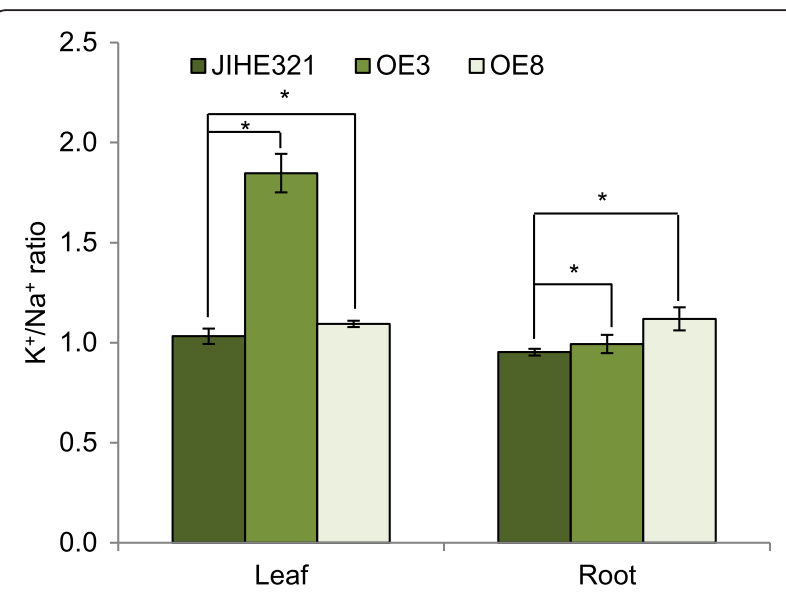

Fig. 6 Ectopic-expression of SAG12:.IPT induces $\mathrm{K}^{+} / \mathrm{Na}^{+}$ratio in cotton leaves. The third true leaf and root samples $(0.5 \mathrm{~g})$ of transgenic lines and control cotton were collected after 220 $\mathrm{mmol} \cdot \mathrm{L}^{-1} \mathrm{NaCl}$ treatment for 7 days. The $\mathrm{K}^{+} / \mathrm{Na}^{+}$ratio was calculated by dividing $\mathrm{K}^{+}$content by $\mathrm{Na}^{+}$content. The data are shown as means \pm SD from three repeats $\left(n=3,{ }^{*} P \leq 0.05\right)$

seedling stage in comparison with control plants, and the same line displayed different tolerance to salt stress at different stages. For example, the OE8 line was more tolerant to salt stress and had more CTKs than the OE3 line during germination (Figs. 1 \& 3), and the OE3 line was more tolerant to salt stress and had more CTKs than the OE8 line at the seedling stage (Figs. 2 \& 4). Different T-DNA insertion loci (Peach and Velten 1991; Iglesias et al. 1997) and copy number of transgenic gene (Hobbs et al. 1990; Elmayan and Vaucheret 1996) could affect the function of exogenous genes. In tobacco, transformants that have a single T-DNA insertion showed high GUS activity, while those that have multiple T-DNA insertions showed low GUS activity due to the increased methylation of the integrated T-DNA (Hobbs et al. 1990). Also, Iglesias et al. (1997) found that the GUS-positive transgenic tobacco lines was attributed to both the transcriptional enhancers located in left flanking plant DNA of the T-DNA inserts and the adjacent to telomeres of inserts (Iglesias et al. 1997). Thus, we speculate that the various salt tolerance from the SAG12::IPT transgenic cotton lines is the result of different insertion loci and copy number of exogenous IPT gene, which possibly altered the CTK biosynthesis by transcriptional or post-transcriptional regulation.

\section{Conclusion}

IPT is a key enzyme involved in CTK biosynthesis and plays an important role in response to abiotic stresses. We generated the ectopic-expressing IPT cotton lines under the control of a senescence-inducible $S A G 12$ promoter. Ectopic-expression of SAG12::IPT induced the accumulation of CTKs in leaves, roots, and the germinating seeds. Furthermore, ectopic-expressing IPT increased the activity of antioxidant enzymes, leading to the reduction of ROS accumulation in cotton leaves. Also, ectopic-expression of IPT increased $\mathrm{K}^{+} / \mathrm{Na}^{+}$ratio in both cotton shoot and root. Our study not only provides a blueprint on generating salt-tolerant cotton lines, but also sheds light on the functional understanding of exogenous $I P T$ gene driven by an inducible promoter in response to cotton salt stress.

\section{Abbreviations \\ AHPs: Histidine-containing phosphotransferase factors; AMP: Adenosine monophosphate; APX: Ascorbate peroxidase; CAT: Catalase; CTK: Cytokinin; DMAPP: Isoamyl groups; iPA: Isopentenyl adenosine; IPMP: Isopentyl adenosine-5- $\beta$-phosphate; IPT: Isopentyl transferase; POD: Peroxidase; ROS: Reactive oxygen species; SAG: Senescence-associated gene; \\ SOD: Superoxide dismutase; ZR: Zeatin riboside}

\section{Acknowledgments}

We appreciate Prof. FU Yongcai of China Agricultural University for kindly providing the plasmid pSG529, and Cotton Research Institute, Shanxi Academy of Agricultural Sciences for generating the transgenic cotton lines. We thank Dr. Kevin L. Cox Jr. for critical reading of the manuscript. The authors have declared no conflict of interests.

\section{Authors' contributions}

Tian XL conceived and designed the study; Zhao P and Shan Y carried out the experiments, analyzed and interpreted the data; Shan Y, Li FJ and Tian $\mathrm{XL}$ prepared the manuscript. All authors read and approved the final version of manuscript.

\section{Funding}

This work was supported by The Genetically Modified Organisms Breeding Major Projects of China Grant (2016ZX08005-004).

\section{Availability of data and materials}

No other data related to this study is available at this time.

Ethics approval and consent to participate

Not applicable.

\section{Consent for publication}

Not applicable.

\section{Competing interests}

The authors declare that they have no competing interests.

Received: 5 May 2019 Accepted: 20 August 2019

Published online: 30 September 2019

\section{References}

Akiyoshi DE, Klee H, Amasino RM, et al. T-DNA of agrobacterium tumefaciens encodes an enzyme of cytokinin biosynthesis. Proceedings Natl Acad Sci USA. 1984;81(19):5994-8. https://doi.org/10.1073/pnas.81.19.5994 .

Ashraf M. Salt tolerance of cotton: some new advances. Crit Rev Plant Sci. 2002; 21(1):1-30. https://doi.org/10.1080/0735-260291044160.

Belintani NG, Guerzoni JTS, Moreira RMP, et al. Improving low-temperature tolerance in sugarcane by expressing the ipt gene under a cold inducible promoter. Biol Plantarum. 2012;56(1):71-7. https://doi.org/10.1007/s10535012-0018-1.

Das K, Roychoudhury A. Reactive oxygen species (ROS) and response of antioxidants as ROS-scavengers during environmental stress in plants. Front Environ Sci. 2014;2:53. https://doi.org/10.3389/fenvs.2014.00053.

Dhindsa RS, Plumb-Dhindsa P, Thorpe TA. Leaf senescence: correlated with increased levels of membrane permeability and lipid peroxidation, and decreased levels of superoxide dismutase and catalase. J Exp Bot. 1981;32(1): 93-101. https://doi.org/10.1093/jxb/32.1.93. 
Dong HZ, Niu YH, Li WJ, et al. Effects of cotton rootstock on endogenous cytokinins and abscisic acid in xylem sap and leaves in relation to leaf senescence. J Exp Bot. 2008;59(6):1295-304. https://doi.org/10.1093/jxb/ern035.

Elmayan T, Vaucheret $\mathrm{H}$. A strongly expressed 35S-driven transgene undergoes post-transcriptional silencing in all tobacco transformants irrespective of the copy number. Plant J. 1996;9:787-97.

Feki K, Quintero FJ, Khoudi H, et al. A constitutively active form of a durum wheat $\mathrm{Na}^{+} / \mathrm{H}^{+}$antiporter SOS1 confers high salt tolerance to transgenic Arabidopsis. Plant Cell Rep. 2014;33(2):277-88. https://doi.org/10.1007/s00299-013-1528-9.

Gupta S, Rashotte AM. Down-stream components of cytokinin signaling and the role of cytokinin throughout the plant. Plant Cell Rep. 2012;31(5):801-12. https://doi.org/10.1007/s00299-012-1233-0.

Ha S, Vankova R, Yamaguchi-Shinozaki K, et al. Cytokinins: metabolism and function in plant adaptation to environmental stresses. Trends Plant Sci. 2012;17(3):172-9. https://doi.org/10.1016/j.tplants.2011.12.005.

Hobbs SLA, Kpodar P, DeLong CMO. The effect of T-DNA copy number, position and methylation on reporter gene expression in tobacco transformants. Plant Mol Biol. 1990;15(6):851-64. https://doi.org/10.1007/bf00039425.

Hu LX, Li HY, Pang HC, et al. Responses of antioxidant gene, protein and enzymes to salinity stress in two genotypes of perennial ryegrass (Lolium perenne) differing in salt tolerance. J Plant Physiol. 2012;169(2):146-56. https://doi.org/10.1016/j.jplph.2011.08.020.

Iglesias VA, Moscone EA, Papp I, et al. Molecular and cytogenetic analyses of stably and unstably expressed transgene loci in tobacco. Plant Cell. 1997;9(8): 1251-64. https://doi.org/10.2307/3870379.

labal K, Azhar FM, Khan IA. Variability for drought tolerance in cotton (Gossypium hirsutum) and its genetic basis. Int J Agric Biol. 2011;13(1):61-6.

Kakimoto T. Identification of plant cytokinin biosynthetic enzymes as dimethylallyl diphosphate: ATP/ADP isopentenyltransferases. Plant Cell Physiol. 2001;42(7):677-85. https://doi.org/10.1093/pcp/pce112.

Kieber JJ, Schaller GE. Cytokinins. The Arabidopsis book, 2014, 12. https://doi. org/10.1199/tab.0168

Leshem YY, Wurzburger J, Grossman S, et al. Cytokinin interaction with free radical metabolism and senescence: effects on endogenous lipoxygenase and purine oxidation. Physiol Plantarum. 1981;53(1):9-12. https://doi.org/1 0.1111/j.1399-3054.1981.tb05037.x

Liu GZ, Li XL, Jin SX, et al. Overexpression of rice NAC gene SNAC1 improves drought and salt tolerance by enhancing root development and reducing transpiration rate in transgenic cotton. PLoS One. 2014;9(1):e86895. https:// doi.org/10.1371/journal.pone.0086895.

Liu YD, Yin ZJ, Yu JW, et al. Improved salt tolerance and delayed leaf senescence in transgenic cotton expressing the Agrobacterium IPT gene. Biol Plantarum. 2012a;56(2):1-10. https://doi.org/10.1007/s10535-012-0082-6 .

Liu Z, Li YE, Tian XL. Impact of leaf senescence and agronomic characters in cotton transformed with ipt gene controlled by promoter sag12. China Cotton Sci-Tech Society. Compilation of the 2012 Annual Meeting and the Eighth Conference of the China Cotton Sci-Tech Society; 2012b. p. 180.

Mantri N, Patade V, Penna S, et al. Abiotic stress responses in plants: present and future. In: Ahmad P, Prasad M, editors. Abiotic Stress Responses in Plants. New York: Springer; 2011. p. 1-19. https://doi.org/10.1007/978-1-4614-0634-1_1.

Mason MG, Jha D, Salt DE, et al. Type-B response regulators ARR1 and ARR12 regulate expression of AtHKT1;1 and accumulation of sodium in Arabidopsis shoots. Plant J. 2010;64(5):753-63. https://doi.org/10.1111/j.1365-313X.2010. 04366.x.

Mason MG, Mathews DE, Argyros DA, et al. Multiple type-B response regulators mediate cytokinin signal transduction in Arabidopsis. Plant Cell. 2005;17(11) 3007-18. https://doi.org/10.1105/tpc.105.035451.

Merewitz EB, Gianfagna T, Huang BR. Effects of SAG12-ipt and HSP18.2-ipt expression on cytokinin production, root growth, and leaf senescence in creeping bentgrass exposed to drought stress. J Am Soc Hortic Sci. 2010;135 (3):230-23991. https://doi.org/10.21273/JASHS.135.3.230.

Mishra N, Sun L, Zhu XL, et al. Overexpression of the rice SUMO E3 ligase gene OsSIZ1 in cotton enhances drought and heat tolerance, and substantially improves fiber yields in the field under reduced irrigation and rainfed conditions. Plant Cell Physiol. 2017;58(4):735-46. https://doi.org/10.1093/pcp/pcx032.

Munns R, James RA, Läuchli A. Approaches to increasing the salt tolerance of wheat and other cereals. J Exp Bot. 2006;57(5):1025-43. https://doi.org/10.1 093/jxb/erj100

Ohkama-Ohtsu N, Radwan S, Peterson A, et al. Characterization of the extracellular $\gamma$-glutamyl transpeptidases, GGT1 and GGT2, in Arabidopsis. Plant J. 2007;49(5):865-77. https://doi.org/10.1111/j.1365-313X.2006.03004.X.
Ort DR. When there is too much light. Plant Physiol. 2001;125(1):29-32. https:// doi.org/10.1104/pp.125.1.29

Pasapula V, Shen G, Kuppu S, et al. Expression of an Arabidopsis vacuolar $\mathrm{H}^{+}$pyrophosphatase gene (AVP1) in cotton improves drought- and salt tolerance and increases fibre yield in the field conditions. Plant Biotechnol J. 2015;9(1):88-99. https://doi.org/10.1111/j.1467-7652.2010.00535.x.

Peach C, Velten J. Transgene expression variability (position effect) of CAT and GUS reporter genes driven by linked divergent T-DNA promoters. Plant Mol Biol. 1991;17(1):49-60. https://doi.org/10.1007/BF00036805.

Qiu WM, Liu MY, Qiao GR, et al. An isopentyl transferase gene driven by the stress-inducible $r d 29 \mathrm{~A}$ promoter improves salinity stress tolerance in transgenic tobacco. Plant Mol Biol Rep. 2012;30(3):519-28. https://doi.org/1 0.1007/s11105-011-0337-y

Rivero RM, Kojima M, Gepstein A, et al. Delayed leaf senescence induces extreme drought tolerance in a flowering plant. P Natl Acad Sci USA. 2007;104(49): 19631-6. https://doi.org/10.1073/pnas.0709453104.

Shi XL, Rashotte AM. Advances in upstream players of cytokinin phosphorelay: receptors and histidine phosphotransfer proteins. Plant Cell Rep. 2012;31(5): 789-99. https://doi.org/10.1007/s00299-012-1229-9.

Sunilkumar G, Campbell LAM, Puckhaber L, et al. Engineering cottonseed for use in human nutrition by tissue-specific reduction of toxic gossypol. P Natl Acad Sci USA. 2006;103(48):18054-9. https://doi.org/10.1073/pnas.0605389103.

Takei K, Sakakibara H, Sugiyama T. Identification of genes encoding adenylate isopentenyl-transferase, a cytokinin biosynthesis enzyme, in Arabidopsis thaliana. J Biol Chem. 2001;276(28):405-10. https://doi.org/10.1074/jbc.M1 02130200 .

Tang DQ, Qian HM, Zhao LX, et al. Transgenic tobacco plants expressing BoRS1 gene from Brassica oleracea var. acephala show enhanced tolerance to water stress. J Biosci. 2005;30(5):647-55. https://doi.org/10.1007/bf02703565.

Thomas JC, Smigocki AC, Bohnert HJ. Light-induced expression of ipt from Agrobacterium tumefaciens results in cytokinin accumulation and osmotic stress symptoms in transgenic tobacco. Plant Mol Biol. 1995;28(5):965. https:// doi.org/10.1007/bf00042081.

Tran L-SP, Urao T, Qin F, et al. Functional analysis of AHK1/ATHK1 and cytokinin receptor histidine kinases in response to abscisic acid, drought, and salt stress in Arabidopsis. P Natl Acad Sci USA. 2007;104(51):20623-8. https://doi. org/10.1073/pnas.0706547105.

Wang C, Lu G, Hao Y, et al. ABP9, a maize bZIP transcription factor, enhances tolerance to salt and drought in transgenic cotton. Planta. 2017;246(6):1-17. https://doi.org/10.1007/s00425-017-2704-X.

Wang Y, Li B, Du MW, et al. Mechanism of phytohormone involvement in feedback regulation of cotton leaf senescence induced by potassium deficiency. J Exp Bot. 2012;63(16):5887-901. https://doi.org/10.1093/jxb/ers238.

Wang YP, Shen WZ, Chan ZL, et al. Endogenous Cytokinin overproduction modulates ROS homeostasis and decreases Salt stress resistance in Arabidopsis Thaliana. Front Plant Sci. 2015;6:1004.

Wojtania A, Skrzypek E. Effects of cytokinins on antioxidant enzymes in in vitro grown shoots of Pelargonium hortorum L. H Bayley Acta Agrobot. 2014;67(4): 33-42. https://doi.org/10.5586/aa.2014.042.

Yuan Z, Pan A, Jian Z. Senescence delay characterization of transgenic Brassica chinensis L. containing an anti-senescence chimeric gene SAG12-IPT. J Plant Physiol Mol Biol. 2002;28(5):379-84. https://doi.org/10.3321/j.issn:1671-3877.2 002.05.010.

Zaharieva T, Yamashita K, Matsumoto $\mathrm{H}$. Iron deficiency induced changes in ascorbate content and enzyme activities related to ascorbate metabolism in cucumber roots. Plant Cell Physiol. 1999;40(3):273-80. https://doi.org/10.1093/ oxfordjournals.pcp.a029538.

Zakizadeh H, Lütken H, Sriskandarajah S, et al. Transformation of miniature potted rose (Rosa hybrida $\mathrm{CV}$. Linda) with $\mathrm{P}_{S A G 12-i p t}$ gene delays leaf senescence and enhances resistance to exogenous ethylene. Plant Cell Rep. 2013;32(2):195205. https://doi.org/10.1007/s00299-012-1354-5.

Zhao P, Gao CX, Zhang N, et al. Study on differentail expression patterns of senescence-associated genes in transgenic cotton with IPT gene. Molecular plant breeding. 2012;10(3):324-30. https://doi.org/10.3969/j.issn.1672-416X.2 012.03.010.

Zwack PJ, Rashotte AM. Interactions between cytokinin signalling and abiotic stress responses. J Exp Bot. 2015;66(16):4863-71. https://doi.org/10.1093/ jxb/erv172. 